\title{
LITERATURA Y CULTURA
}





\section{LA ENSEÑANZA DE LA CULTURA Y DE LA LITERATURA EN L2: LA PERSPECTIVA DE LOS TRABAJOS DE GRADUACIÓN EN LA MAESTRÍA EN ESPAÑOL COMO SEGUNDA LENGUA}

Jorge Chen Sham

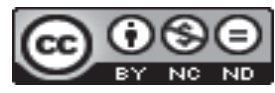

Esta obra está bajo una licencia Creative Commons

Reconocimiento-No Comercial-Sin Obra Derivada 



\title{
LA ENSEÑANZA DE LA CULTURA Y DE LA LITERATURA EN L2: LA PERSPECTIVA DE LOS TRABAJOS DE GRADUACIÓN EN LA MAESTRÍA EN ESPAÑOL COMO SEGUNDA LENGUA
}

\author{
TEACHING CULTURE AND LITERATURE IN L2: A PERSPECTIVE FROM \\ MA GRADUATE PROJECTS IN SPANISH AS A SECOND LANGUAGE
}

Jorge Chen Sham

\begin{abstract}
RESUMEN
El enfoque comunicativo y el postulado de la interculturalidad constituyen un aporte a la didáctica de la cultura y la literatura en L2, que está acometiendo la Maestría en Español como Segunda Lengua desde su fundación en 1998. Se trata de una agenda educativa con vocación americanista pues profundiza en los elementos constituyentes del devenir histórico de América Latina y se decanta por una propuesta curricular para la enseñanza y la crítica literaria que identifique sus claves culturales. Este artículo presenta una síntesis de un proyecto académico e institucional que, en la Universidad de Costa Rica, motivan, por un lado, el desarrollo actual de la enseñanza del Español como Segunda Lengua y, por otro, la necesidad de incluir la literatura en tanto material auténtico, no como un apéndice sino con su lugar de privilegio en las clases de español para extranjeros.

Ya sea la conciencia del respeto de la diversidad cultural o de la cultura-meta, ya sea el mejoramiento de la competencia narrativa y sus técnicas, los trabajos que se han desarrollado en nuestra Maestría se insertan en esa perspectiva de la investigación-acción en la que solamente el docente es capaz de mejorar su entorno dentro de "una enseñanza para la comprensión" e interactúa así con sus estudiantes.

Palabras clave: Didáctica de la Literatura, Español como L2, crítica literaria, Maestría en Español como Segunda Lengua, interculturalidad.
\end{abstract}

\begin{abstract}
The communicative approach and the postulate of multiculturalism constitute a contribution to the teaching of culture and literature in L2, undertaken by the Master of Spanish as a Second Language since its founding in 1998. It is an educational agenda with Americanist vocation as it delves into the founding elements of the historical development of Latin America and opts for a curriculum for teaching and literary criticism that identifies its cultural cues. This article presents a synthesis of an academic and institutional project at the University of Costa Rica, that propels, on the one hand, the current development of the teaching of Spanish as a Second Language and secondly, the need to include literature as authentic material, not as an appendix but from a privileged place in Spanish classes for foreigners. Be it awareness of respect for cultural diversity or meta-culture, be it the improvement of narrative competency and techniques, the work that has been developed in our Master program are inserted into this perspective of action-research in which the teacher alone is able to improve their environment within a "teaching for understanding" and thus interact with their students.

Key words: Pedagogy of Literature, Spanish as a L2, Literary Criticism, Master in Spanish as a Second Language, Multiculturalism.
\end{abstract}

Dr. Jorge Chen Sham. Universidad de Costa Rica. Profesor Catedrático. Escuela de Filología y Lingüística. Costa Rica. Miembro correspondiente de la Academia Nicaragüense de la Lengua y la Academia Norteamericana de la Lengua Española.

Correo electrónico: jorgechsh@yahoo.com

Recepción: 28- 08- 2015

Aceptación: 04- 09- 2015 
Este trabajo se propone como la síntesis de un proyecto académico e institucional que, en la Universidad de Costa Rica, terminó con la creación de la Maestría Profesional en Segunda Lengua, bajo el liderazgo de la profesora M. L. Flor Garita Hernández, quien ahora se encuentra en su merecida jubilación. Casi única en su campo, porque ofrece no un diplomado (estudios de dos años), sino estudios de maestría a nivel profesional, a finales del siglo pasado se consolida un espacio de reflexión que conjuntó la lingüística aplicada, la didáctica de la lengua y la literatura, así como la enseñanza de L2. Esta opción académica al mismo tiempo permitió ofrecerles a los graduandos de filología española, linguiística, inglés o francés, que ya venían trabajando en la enseñanza del Español como Segunda Lengua en Costa Rica, una acreditación académica que avalara el trabajo que ya ofrecían en este campo laboral.

En la últimas década del siglo XX, el auge del turismo masivo, la oferta de Costa Rica como un paraíso ecológico, las bondades de su sistema de vida y de su desarrollo social y excelente clima político, todo ello contribuyó a la entrada de nuestro país en la globalización socio-económica y que se convirtiera en un sitio para que: a) las universidades extranjeras empezaran a enviar y a firmar convenios de cooperación institucionales con el fin de que sus estudiantes estuvieran inmersos en la cultura meta, y b) turistas en largos periodos de viaje quisieran aprovechar la oportunidad de su estadía para aprender en forma sistemática los rudimentos de la lengua de acogida. No cabe duda de que la firma y la ejecución de convenios de cooperación entre la Universidad de Costa Rica y instituciones superiores de enseñanza propició este auge de la enseñanza del Español en la forma de programas de inmersión, con el fin de satisfacer las demandas propias a la adquisición de una L2, pues se trata "de los negocios y del comercio, de la ciencia y de la tecnología y de las relaciones internacionales y la diplomacia" (Larsen-Freeman y Long, 1994, p. 13) en un mundo más conectado y globalizado.

Se preguntará el lector las razones por las cuales se promovió esta maestría como de tipo profesional en nuestro ordenamiento jurídico y no de tipo académica. Razones de mercado laboral fueron las que imperaron para que se optara sobre todo por esta salida, porque una maestría académica implicaba la realización de una tesis de grado de carácter demostrativo y argumentativo. Más bien, los que iniciaron esta Maestría se decantaron por la profesional, por las facilidades que proporcionaba a la hora de reunir un componente laboral práctico y la confección de una propuesta didáctica que los estudiantes podían ir a implementar/desarrollar en la clase. También obedecía a una prioridad nacional en el sentido de que había, en la Costa Rica de finales del siglo XX y principios del XXI, una serie de profesores empíricos (graduados en disciplinas relacionadas con la lengua y la literatura, aunque también había muchos que lo eran) trabajan en este dominio pero que no tenían, ya sea el título profesional que los acreditara para ello, ya sea el marco de referencia que les permitiera encontrar las respuestas a los problemas encontrados en el aula. En este sentido, la realidad social y educativa por discernir era que teníamos profesores empíricos y que, a través del error/solución en su trabajo diario o con arreglo a la didáctica en general, debían de enfrentarse a problemas y a ajustar su función docente, sin estar preparados para la especificidad de la enseñanza en L2.

A estos estudiantes que ingresaron en las primeras promociones de la Maestría en la Enseñanza del Español como Segunda Lengua les sucedió lo que preveía John Elliot en el paradigma de la investigación-acción, cuando indicaba que el profesor debía relexionar sobre "el concepto de aprendizaje para la comprensión y [compenetrarse con] la concepción del profesor como profesional autónomo que investiga reflexionando sobre su propia práctica" (PérezGómez, 2005, p. 10). Se trata, entonces, de reflexionar sobre su propio trabajo docente y, en 
esto, quisiera insistir en que los cursos de nuestra Maestría, les permitió tanto una comprensión reconstructiva simple, la cual requiere "la capacidad de entender la información de entender la información en términos de conceptos e ideas referentes a la misma" (Pérez-Gómez, 2005, p. 14), para pasar luego a la comprensión reconstructiva global, cuya "capacidad de situar la información en el marco de ideas y procedimientos claves que estructuran el pensamiento en el seno del ámbito disciplinar concreto" (Pérez-Gómez, 2005, p. 14). Lo anterior supone que el estudiante tenía esa capacidad de elaborar problemas y cuestionar la teoría proporcionada para enriquecer su práctica docente, la mayoría de las veces empírica. Si como indicaba Elliot, el paradigma de la investigación-acción analiza las acciones humanas y situaciones sociales que el trabajo en el aula les generaba (Elliot, 2005, p. 24), ellos requerían de respuestas prácticas que solamente si se tenía una comprensión de la situación, podrían enfrentar con las herramientas metodológicas y las propuestas teóricas ofertadas para encuadrar y poder realizar un diagnóstico tendiente a establecer objetivos y a seleccionar "cursos de acciones" (Elliot, 2005, p. 25). Se trataba, entonces, que los trabajos de graduación fueran prácticos y formularan un problema, ofrecieran conceptos sensibilizadores; que sus datos de investigación tuvieran una tendencia hacia lo cualitativo, desarrollaran una teoría sustantiva en el aula porque apuntaban hacia un curso de acciones, mientras validaban que estas acciones fueran de tipo naturalistas, es decir, en el sentido de que "hac[ían] generalizaciones acerca de una clase de acción sobre la base del estudio de una muestra" (Elliot, 2005, p. 36). Todo ello contribuye, en efecto, sobre el trabajo diario en el aula ofreciéndole al docente la oportunidad de reflexionar e investigar sobre su propia práctica docente.

En cuanto al lugar de la enseñanza de la Cultura y de la Literatura en el curriculum de la Maestría en Español como Segunda Lengua este no es un apéndice ni tampoco es ancilla dominae. No es ni algo agregado ni tampoco está al servicio de la enseñanza de la lengua. Tres cursos hay en nuestro curriculum: dos cursos llamados "Claves culturales" y uno sobre "La literatura latinoamericana en la enseñanza de L2". Representan casi un tercio de los cursos programáticos. La perspectiva en los dos primeros es que solamente manejando los códigos maestros de la cultura meta se puede superar esa perspectiva de una lengua desligada de su historia y de aquello que la informa y le proporciona su especificidad sociocultural; hacerlo de la manera tradicional deja al estudiante sin esas herramientas para acercarse una competencia intercultural. Sus procesos históricos, la conformación de las sociedades, los nexos y el intercambio comercial, los movimientos sociales, todo ello contribuye a configurar el territorio americano y sus herencias coloniales que arrastramos hasta hoy día.

Queda claro que una didáctica de la literatura debe proponerse la tarea de percibir que la literatura guarda relaciones estrechas con otros discursos sociales y estéticos en el marco de una sociedad y ello incide en el debate pedagógico actual, en la manera en que enseñemos una determinada práctica de leer/interpretar los textos literarios y que el análisis crítico tenga como objetivo el formar también un lector "capable d'utiliser des instruments critiques (mais pas forcément un spécialiste), une personne consciente de ses choix et des ses goûts" (Bertoni, 1988, p. 150). En este sentido, una didáctica de la literatura en general se orienta hacia:

1. Ubicar mejor los textos literarios en sus justas dimensiones en relación con otras obras y con respecto a las motivaciones socio-culturales en las que se inscribe su dinámica histórica; 
2. Relacionarlos con un patrimonio individual y colectivo del que son siempre una expresión cultural;

3. Confrontarlas con la experiencia de lectura de otras obras literarias y artísticas y también culturales (de ahí el imput que esto posee en la didáctica de L2), con el fin de ampliar las resonancias críticas, pues interesa "prendre place dans notre horizon, relative à notre encyclopédie et à notre connaissance du monde" (Bertoni, 1988, p. 155).

Observemos que se cuestiona la idea de la enseñanza de un catálogo de obras y autores, los cuales se explican mediante un contexto socio-histórico, ni tampoco es un complejo aprendizaje de técnicas críticas para el análisis de texto. La didáctica de la literatura ha sido esa actividad que ha estado relegada a segundo plano en el furor epistemológico y en la progresión de la crítica literarias del último tercio del siglo XX, para las cuales lo didáctico reñía con su proyecto de una crítica sistemática y metódica, frente a los criterios de una pedagogía centrada en la supremacía de la individualidad del autor o en la memorística de los rasgos de periodización literaria (Gueunier, 1977, p. 143). Por su parte, Carlos Lomas e Inés Miret redireccionan y afinan una didáctica de la literatura en general: el "texto literario aparece ahora como un tipo específico de uso comunicativo mediante el cual las personas intentan dar sentido a la propia experiencia [añadiríamos nosotros, cultural], indagar sobre su identidad individual y colectiva" (Lomas y Miret, 1999, p. 7). Es lo que priva en el curso de "La literatura latinoamericana en la enseñanza de L2", al proponerle al estudiante que esos nexos y claves encontradas ahora se dirijan al terreno de la historia literaria. Se trata de plantear que la literatura es una fuente inagotable y la más rica para analizar, en su lenguaje, en su cosmovisión, en su retórica y referencias culturales, cómo piensa, cómo se construye, cómo se identifica y se mira un pueblo, un país, una sociedad en un momento determinado de su historia.

Pero, ¿en qué noción de cultura se está pensando? Desde un punto de vista ideológico en el sentido de la cohesión/identificación que ella promueve, Phillip Block la define como "todas las expectativas, modos de ver, creencias o acuerdos que influyen en el comportamiento de los miembros de un grupo humano" (1985, p. 31), mientras que Edmond Cros subraya tales funciones pero agrega lo identitario en este proceso de apelación/integración, cuando la expone como "el espacio ideológico cuya función objetiva consiste en enraizar una colectividad en la conciencia de su propia identidad" (2003, p. 11). La cultura no es así algo previo ni solidificado, es dinámica y está configurada por su movilidad histórica, al tiempo que incluye valores, ideas, creencias, productos y prácticas. Es más, la cultura no es en sí un fenómeno material, sino que ella se informa (cobra materialidad física realizándose en instituciones, actividades, símbolos, experiencias, lenguajes y clasificaciones). De carácter histórico y enraizada en un tiempo/ espacio, la cultura corresponde a la conceptualización que se haga de ella en un momento determinado, de tal suerte que se pondere su comparación y contraste con otras culturas, dentro de lo que la teoría estructuralista planteaba como valor diferencial (de comparación contrastiva), al hacer surgir tanto el valor como la especificidad.

He ahí el gran reto de la interculturalidad y de la enseñanza de la cultura meta en L2, porque en la enseñanza de un idioma extranjero el estudiante se confronta con las expresiones de una cultura, de la que no puede ni sustraerse él ni su profesor y que el lenguaje vehiculiza en tanto contenido social. Allí en donde la cultura previa del estudiante desempeña ese punto de cruce hacia la cultura meta, en esta encrucijada debe negociar, descodificar, interpretar, "sin 
morir en el intento", parafraseando al gran cineasta español Almodóvar. Este flujo o dinámica intercultural es muy difícil de lograr y supone el grado más elevado a la que aspira una competencia intercultural, en todo lo que ella tenga de respeto, tolerancia, miedo, prejuicios, estereotipos, miedos, afectos, emociones, incertidumbres, etc. Y, siguiendo a Pamela L. Tiedt e Iris M. Tiedt, los objetivos indiscutibles de una educación multicultural serían: "esteem, empathy and equity" (2002, p. 38), cosa que la literatura promueve tanto por su diversidad como por su complejidad.

Desde un principio los trabajos de graduación en nuestra Maestría se decantaron por esta perspectiva de activar o propiciar una competencia intercultural que permitiera integrar el componente comunicativo y pragmático, para que fuera una herramienta esencial y de gran potencial en la enseñanza/aprendizaje del Español como L2. Quisiera referirme a algunos de los trabajos, no los he escogido porque haya creído que representen los más acabados y desarrollados con pertinencia, sino porque me permitirán dar cuenta de dos tendencias en la enseñanza de la cultura.

El primero es el de Libia Hernández Morales con el título de La enseñanza de la cultura desde una perspectiva pragmático-situacional, del año 2004. Atendiendo a un enfoque sociolingüístico, se pregunta Libia Hernández por aquellas fuentes de "mala comunicación intercultural" (2004, p. 17) y sus efectos sociales que acarrea cuando alguien sabe o no sabe cómo se agradece, se disculpa o se felicita por algo; todo ello se engloba dentro de la cortesía verbal, para que los interlocutores generen aceptación o lo contrario, malos entendidos. Ella parte de la hipótesis de que estos actos de habla y su uso en situación pueden aprenderse o perfeccionarse si se sabe utilizar mitigadores léxico y sintácticos, para lograr una perfecta comunicación, o generar la respuesta indeseable y por lo tanto, el rechazo y la censura (2004, p. 32). Es decir, el éxito para pedir algo, para obtener una respuesta, el fin perlocutivo depende, para el hablante no nativo, del nivel de inmersión en la nueva cultura, qué tanto conozca su idiosincracia, como pueda negociar con las palabras y comunicarse con la eficiencia y la asertividad requeridas. Un ejemplo de ello lo pone Hernández-Morales en su unidad didáctica "Negociemos con palabras", cuando el objetivo es salir de compras y pone a los estudiantes a practicar con actos de habla tales como la petición, la solicitud, el reclamo o el rechazo (2004, p. 72). Por supuesto que ella ha repartido un vocabulario básico y los pone en parejas para practicar estos actos en una situación dramatizada o ficticia: "se le acerca una persona que quiere iniciar una conversación con usted" o un "mesero le lleva una orden equivocada" (2004, p. 74), frente a las cuales deben escoger e interactuar los estudiantes.

En relación con lo contextual y su significado, llama la atención el énfasis que Libia Hernández otorgó a la "Idiosincracia del tico", lo que ella denominó como "manera de ser del tico" (2004, p. 68), con el fin de "Facilitar la comprensión de algunas formas de interacción con las personas de la nueva cultura" (2004, p. 68) y pone en el tapete procedimientos que tienen que ver con los cumplidos “¡Ud. se ve muy bien hoy!", o con el manejo más distendido del tiempo y de la cortesía en la frase "Ahorita no, gracias" (2004, p. 69). En la frase aseverativa "Lo (a) llamo más tarde" le pregunta al estudiante ¿qué quiere decir ? Y nos presenta cinco opciones:

"Es mejor que no me llame"

"No hay por qué preocuparse"

"Seguro ya sabré si: sí o no" 
"No voy a tener tiempo antes"

"Me gustaría verte, pero no sé si puedo hoy" (2004, p. 81)

De lo anterior, hay que deducir el significado de la frase y los contextos de aplicación y, para ello, ella recalca la importancia de la entonación y de la actitud del hablante. Yo agregaría otra de esas frases que producen incertidumbre en el extranjero ante la idiosincracia del tico: “¿Cuándo nos tomamos un café?”. El extranjero se quedará esperando la invitación que no se concreta, cuando se trata de una forma de cortesía, por supuesto, de convivencia y de búsqueda de una actitud positiva ante el otro.

Mucho más elaborado pero no por eso menos complejo que el anterior, es el trabajo de graduación presentado por Silvia Montero Chacón con el título de La enseñanza de la cultura hispanoamericana desde la perspectiva del mestizaje y sus manifestaciones culturales, también del año 2004. Montero-Chacón escoge una de esas claves maestras en la comprensión de la cultura meta como es el concepto de "mestizaje". Ella parte de un cierto perfil del estudiante para la cultura y la literatura en L2; lo presenta como interesado en temas culturales, capaz de abstraer y preguntarse; con destrezas para describir y narrar, trabajar en grupo y realizar actividades grupales, además de debatir y defender ideas, todas muy propias de un estudiante del nivel avanzado según la escala ACTFL (Montero-Chacón, 2004, p. 46), es decir, que pueda integrar las cuatro habilidades: habla, escucha, lectura y escritura. Montero-Chacón, selecciona para abordar el mestizaje en forma transversal muestras representativas haciendo un recorrido por la diversidad latinoamericana: del México, con sus manifestaciones como pueden ser el muralismo y su visión de la Revolución Mexicana, la variada y exquisita gastronomía o el catrín y su relación con el Día de Muertos; pasa a Cuba, en donde también aborda la religión de la santería y el "sabor" de la cocina cubana, para terminar en Argentina, en los orígenes periféricos y arrabaleros del tango y experimentar también su gastronomía.

Como vemos, Montero-Chacón escoge muestras representativas que ya han sido estereotipadas para la presentación de la cultura, música, arte y cocina. Entonces, ¿en qué radica su diferencia y, sobre todo, cómo intentar superar el cliché y el estereotipo? Y, en segundo lugar, ¿cómo alejarse del tipo manual de cultura y civilización en el que, muchas veces, la condensación y la representatividad da paso, sin que se quiera, a una idea simplista de la realidad cultural? Ella parte de la noción de "marcador cultural" (2004, p. 18) en cuanto origen a las diversas claves de una diversidad que ha definido desde el principio como colonial, híbrida, de búsqueda identitaria, machista, mariana y con una visión de mundo sufrida y paradójicamente intensa y alegre (2004, p. 18). Por lo tanto, esta motivación inicial y sus supuestos de base fueron el arranque perfecto para la familiarización, que luego continuó con la preparación y confección de materiales, diseño de la clase y de una ambientación propia, porque lo señala Montero-Chacón, todo se inicia en ese "proceso de apreciación de las similitudes y diferencias entre la cultura meta y la propia" (2004, p. 39), para que de esa relevancia, reflexiva, el estudiante se acerque a su propia cultura a través de la oportunidad que le brinda la otra de renovar su posición o sus puntos de vista (eso es lo que se denomina como el espacio intercultural). Enfatizar diferencias y matizar eso es válido, pero también ofrecerles a los estudiantes la posibilidad de un contacto más personal y cercano con la preparación de recetas de cocina, entrevistas, salidas, ver películas, cantar canciones, porque de lo teórico se pasa a una cierta práctica cultural para no seguir mirando "con ojos de desinterés o incredulidad" (2004, p. 41), indica ella, y yo agregaría de distanciamiento cultural o de pose eurocentrista. 
Quisiera retomar, por ejemplo, la unidad dedicada a México; Montero-Chacón les pidió que revisaran aspectos de la historia mexicana y para ello distribuyó un material previo. Cuando llegaron a la clase, las paredes estaban empapeladas con láminas sobre muralismo mexicano, indica ella (2004, p. 73); como en un museo, las estudiantes las recorrieron y ese itinerario despertó mejor el interés que luego se concretó en la puesta en discusión grupal, al apuntar el sincretismo pictórico de los rasgos indígenas en el color de piel y la presencia del pueblo, la presencia de rituales católicos y símbolos indígenas. Por su parte, la lección sobre el Día de Muertos empezó con la estrategia de hacer preguntas y pasar tanto el ritual azteca como el católico sobre la muerte, que las estudiantes expusieron, para concluir con el altar de los muertos y su confección, el cual tuvieron que hacer in situ, además de confeccionar una "calaca" (2004, p. 74).

Ana Elena Castillo Víquez en Propuesta metodológica para la enseñanza de la literatura latinoamericana a partir de las claves culturales en una clase de hablantes no nativos del Español (2003), parte de esa pregunta que muchos se hacen en L2, ¿para qué estudiar la literatura? (2003, p. 6) y lo hace en un contexto general en el que la forma tradicional de la enseñanza del Español en L2 se resiste y la cataloga en general de "irrelevante" o "carente de importancia" y, más en concreto, se rechaza su estudio o se utiliza en forma de propedéutica para la enseñanza solamente del componente de la lengua. ¿Cuál sería el modelo típico? El ejemplo lo proporciona Castillo-Víquez y es el que ofrece Concepción Bados Ciria, en Español, lenguaje extrajera: textos literarios y ejercicios, en donde cada cuento corto en estudio viene aparejado con la clásica biografía del autor, una lista de vocabulario y termina con algunas preguntas de contenido y de uso de algunas figuras o palabras para la comprensión de cada uno de los cuentos (2001). Siguiendo el enfoque comunicativo porque se requiere la participación activa del estudiante, hay varios principios que me parecen básicos en el trabajo de Ana Elena Castillo-Víquez: el énfasis en que se logre la comunicación porque el objetivo es la competencia socio-discursiva; se trata de un proceso que promueve la auto-gestión y la co-responsabilidad, para que la mediación pedagógica sea, según ella, la plantea:

\footnotetext{
1. Un proceso y no un resultado, por lo que interesa más bien que se comuniquen los estudiantes.

2. Un proceso cuya meta no es la acumulación, sino la interrelación. ${ }^{1}$

3. La comunicación debe ser relevante, de interés y de motivación hacia el estudiante, de ahí la preparación de los materiales, ricos y variados.

4. El profesor constituye un mediador, por lo que la clase debe ser participativa. (2003, p. 44)
}

Castillo-Víquez comienza planteando que, en los estudiantes de L2, la literatura puede "aumentar su confianza y competencia" (2003, p. 10), pero ella plantea que solamente se puede realizar en el marco citado. Avanzado hacia su propuesta metodológica, ella parte de la hipótesis de trabajo de María Amoretti en sus clases, cuando ella impartía los cursos de civilización y literatura en nuestra Maestría y que luego plasmó en su libro Didáctica de la literatura en la enseñanza de segundas lenguas ${ }^{2}$ de que la clave sería la identidad y el sujeto cultural latinoamericano (2007, p. 21) y "la escucha de los diferentes acentos de la palabra" (Amoretti-Hurtado, 2007, p. 20). Tal y como estos se configuran a la luz de ese momento de caos/destrucción que representa el mal llamado "encuentro de culturas", no solamente explicarían aspectos históricos, sociales o econo-políticos, sino la representación del poder y la autoridad, la posición ante la familia o las relaciones entre hombres y mujeres, nuestro acervo y patrimonio cultural.

Desde un punto de vista teórico literario, Castillo-Víquez escoge el deconstruccionismo de Jacques Lacan y sus discípulos norteamericanos, porque el proceso de la différance, y no 
différence en francés (2003, p. 34), constituye la base de un sistema interpretativo en el que ser diferente y su puesta en el tiempo histórico es un trabajo de relevancia y de significación. ¿Qué expresa esto? Si la ausencia/presencia de la identidad latinoamericana es el producto de ese sujeto cultural que desde el Cronotopo de Indias se conformó, no debería verse solamente en forma de una falta o de búsqueda supletiva de deseo siempre de querer ser. Tamaño problema epistemológico en el que se enfrasca Castillo-Víquez y que hace de su propuesta de alto calado filosófico. En la práctica, al querer por ejemplo, poner en juego conceptos como hibridez, colonial y búsqueda de identidad en mitos, su "Unidad I" quiere partir de dos cuentos del costarricense Carlos Salazar Herrera, "La sequía" y "El mestizo", con el fin de encontrar en ellos los mitos fundantes en la cultura latinoamericana. Así la huella de la différance derridiana en estos cuentos, le ayuda a rastrear el entramado de mitos que el análisis deconstruccionista le permitirá realizar: mitos de creación/destrucción del Popol Vuh y de la Biblia (2003,p. 61), Colón y la descripción de La Española, fray Bartolomé de Las Casas y su Brevísima Destrucción de las Indias en tanto voces de los mitos fundadores de la hibridez y de una posición colonialista, para concluir su propuesta de lectura con la película “The Mission” y, de ahí, de nuevo hacia los textos de Salazar Herrera. Resalta ella que hubo poca motivación al inicio cuando se detuvieron en el texto sagrado de los maya-quichés el Popol Vuh; pero que cuando volvieron al Génesis y al mito de creación, el interés aumentó. Los fragmentos de Colón y de Las Casas estimularon la motivación grupal, para generar no solo el involucramiento en el trabajo de clase de los estudiantes, sino que los comentarios de la discusión hecha fueron ricos (2003, p. 73).

Emilia Ma. Villalobos Vega, en El relato corto como artefacto pedagógico (2011), expone que la literatura y, en particular, el relato corto puede ser un "asimilador cultural" como medio para enseñar y estimular estrategias narrativas, por lo que se propone, dentro de esa competencia comunicativa, producir/comprender el lenguaje en su contexto. Se trata de una capacidad que Villalobos-Vega planteará como "competencia narrativa", porque se relaciona con uno de esos grandes problemas al que se enfrentan estudiantes de Español en L2, y es el pretérito y su valor aspectual, porque de lo que se trata es que no solo se pueda comprender textos en pasados sino también reproducirlos/elaborarlos $(2011$, p. 9). Aunque esto se ha hecho sobre todo en el ámbito de los cursos de conversación en forma de ejemplos tomados de la literatura, plantea ella que el énfasis ha sido recurrir a cuentos para practicar estructurales gramaticales, ver modismos o expresiones idiomáticas en contexto. Obsérvese, entonces, cómo en Villalobos-Vega un componente que siempre se ha topicalizado como propio de la enseñanza de la escritura y de la oralidad, tiene un sentido primordial aquí, más allá de privilegiar el uso de un material auténtico. No se ha estado restringido en esta categoría de "material auténtico" limitado a la literatura, cuando en la Maestría en Español como Segunda Lengua literatura se ha utilizado en un sentido más laxo, pues se incluyen canciones, vídeos, caricaturas, películas, prensa periódica, revistas, vídeos.

En el caso de la narrativa, pero es válido también para todas estos materiales auténticos citados más arriba, si de lo que se trata es que las experiencias personales se ajustan a la forma en la que cada cultura las expresa/codifica (Villalobos-Vega, 2011, p. 19), solamente una competencia cultural permitiría una comprensión/confrontación coherente y satisfactoria. Ya de por sí la enseñanza de la cultura y literatura en L2 estaría justificada; pero cuando en el caso específico de la narrativa, permite evaluar y orientar las acciones y los eventos, la manera cómo se perciben las acontecimientos y sus relaciones en el tiempo/espacio, ya entonces el objetivo rebasa lo "estrictamente literario". Para ello, Villalobos-Vega se decanta por el relato 
corto, pues su extensión y su brevedad contribuyen al tiempo del trabajo en aula y a la eficacia de objetivos muy concretos. Su esquema metodológico implica una estrategia de lectura en cuatro pasos: ${ }^{3}$ a) la prelectura del texto: b) la identificación de elementos principales así como detalles; c) una revisión de la estructura narrativa en su relación lógica con causa/efecto, consecuencia y nueva información; y d) la recreación del texto mediante esquemas culturales o intertextuales, con el fin de activar la experiencia previa (2011, p. 48). La primera unidad didáctica, por ejemplo, se decanta por el relato corto del guatemalteco Augusto Monterroso, "El eclipse", cuya temática versa sobre la clave cultural del "encuentro de culturas y la hibridez"; ella presenta un marco de referencia teórico e histórico que le permite conceptualizar la unidad y su interpretación. Es primordial esto para que el profesor sepa diseñar de forma satisfactoria y pertinente su unidad didáctica (muestra su trabajo y preparación previa, lo que antes se denominaba la planificación del trabajo del aula y los ejercicios), así como buscar los materiales que acompañen el trabajo en el aula.

La finalidad de esta estrategia didáctica es al final, luego de seguir los cuatro pasos de su metodología, que se hagan, por supuesto y en primer lugar, preguntas de contenido sobre el relato; se promueva extraer sus ideas centrales mediante preguntas comprensivas de análisis y los estudiantes participen también con la escritura y en una puesta grupal acerca de lo que les llamó la atención; para pasar a una competencia narrativa propiamente dicha y Villalobos propone que se hagan las siguientes tareas, se busque/ se seleccione el momento de mayor atracción/atención en el relato, qué otro título se pondría, cómo podría iniciarse el relato y qué elementos podría tener en forma optativa (2011, p. 97).

Por lo tanto, de este breve recorrido por cuatro trabajos realizados en la Maestría en Español como Segunda Lengua, se podría inferir dos líneas básicas. La primera de tendencia más pragmática y socio-discursiva, destaca claves culturales y las explicita en una diversidad de materiales auténticos y prácticas discursivas, de las cuales la literatura es solamente una de las de mayor prestigio aunque no la única, pues hay otros tipos de textos que pueden ser convocados: prensa escrita, caricatura, canción popular y nueva trova, hasta materiales del folclore tales como leyendas y refranes en donde la cultura se comparte cotidianamente. Pero también existe una apertura hacia otras formas semióticas en las que la cultura se manifiesta; la música, el arte en general, la cocina, el baile son expresiones de tal enriquecimiento de la diversidad y de la complejidad cultural. El problema, entonces, radica en la forma de integrarlas bajo esa conciencia de "identidad cultural", para que el curriculum desarrolle una competencia intercultural, que para Miguel Rodrigo Alsina debe producir esa sinergia de dos componentes, el cognitivo y el emotivo (citado por Montero-Chacón, 2004, p. 14); el primero alude a una actividad de construcción de sentidos en el marco de una comprensión basada en exclusiones/ inclusiones de lo propio y de lo no propio (siempre es del orden de la negociación), mientras que el segundo se logra cuando en la transferencia hacia los otros se logra aceptar las diferencias en el desarrollo social e histórico, con lo cual se propicia la interacción y el acercamiento basado en la empatía y la tolerancia (Montero-Chacón, 2004, p. 15). Este enfoque construye, entonces, aseguran Janet Swaffar y Katherine Arens, un "holistic curriculum" que parte de un curso de decisiones por seguir en cuanto al tipo de materiales y su complejidad por un lado y, por otro, a los intereses y motivaciones de los estudiantes (2005, p. 57); debe también integrar, en un nivel amplio, la cultura visual y auditiva para las cuales hoy en día las nuevas generaciones de estudiantes están más capacitados y familiarizados; ellas agregan: "In a real sense, every reader is a novice reader of texs on some topics: most readers lack cultural background, key information, 
or certain kind of language knowledge in one area or another" (2005, pp. 62-63). Unas líneas más adelante en su argumentación, apuntan hacia el objetivo de establecer comparaciones y conexiones con la cultura meta a partir de estos tipo de textos o materiales, "because it focuses the reader's attention on appropriate connections of language and cultural elements, on culturally similar or dissimilar patterns between the two texts" (2005, p. 63).

La segunda es más eminentemente técnica, eso es cierto. Parte de la idea de que la didáctica de la literatura se transforme en una actividad cuya finalidad sea a la vez lúdica y creativa en su sentido etimológico. Al movilizar esta capacidad para actuar (actualizar y modelar) según los esquemas cognitivos, psico y socio-culturales que el texto despierta en el lector, la lectura literaria se vuelve un trabajo metonímico como diría Roland Barthes (1980, p. 7) porque es: a) bricolage, montar/desmontar, componer/descomponer, actividades que se apoyan sobre el repérage, el descubrimiento de marcas y del funcionamiento del material cultural sobre el que se construye el texto literario (Picard, 1984, p. 259); y b) mientras que el ejercicio activo de montaje/desmontaje, composición/descomposición se base en claves que permitan una mejor comprensión de la cultura y de la identidad gracias a los códigos que las sustentan. Desde esta perspectiva, los dos modelos enunciados no son excluyentes, más bien son complementarios y, en todo caso, el primero sirve de marco de referencia epistemológico al segundo, para confrontar al estudiante con lo que Gillian Lazar observa como objetivo final de cualquier introducción de la literatura en la enseñanza de L2; ella afirma lo siguiente: "Literature for personal enrichment: Involving students: [...] is a useful tool for encouraging student to draw on their own experiences, feelings and opinions" (2005, p. 39).

A su vez, la didáctica a la que apunta esta manera de concebir la cultura y el texto literario da cuenta de la pluralidad y el sentido de pertinencia que debe tener todo ejercicio de lectura. Precisamente, el enfoque comunicativo es el privilegiado en estas propuestas analizadas anteriormente y no es inocente que así sea por su consideración sobre la interculturalidad basada en principios del diálogo, de confrontación y de interrogantes; permite un enfrentamiento al que obliga al estudiante con la cultura de base y la cultura-meta. Coinciden, además, en que la literatura es, ante todo, un material auténtico que permite integrar la experiencia y el saber de una comunidad cultura. Leer es ante todo, una actividad de construcción que conduce a un universo imaginario, decía con gran propiedad Michel Riffaterre (1979, p. 86), eso es cierto; pero los fenómenos de estructuración textual son complejos y requieren de ese nivel referencial, en donde el manejo del código lingüístico y las destrezas de lecto-escritura, son solamente una herramienta de base, para luego explorar otros niveles de significación en los que la connotación y los procesos simbólicos se vuelven de una riqueza inapreciable. Para ello, Gillian Lazar nos recuerda que debemos tanto planear el uso del metalenguaje apropiado de la crítica literaria, como saber dosificar y seleccionar la complejidad de los materiales en el aula; en cuanto a lo primero, que siempre es una "cuestión palpitante" en L2, ella suscribe la idea de que el uso de la terminología y la apropiación de las técnicas y procedimientos siempre estimula al estudiante hacia esa profundización en el texto literario, al tiempo que se siente reconocido de saber emplearlo en su lectura; agrega lo siguiente: "Literary terminology provides students with the tools for identifyng distinctive features in a literary text and so appreciating it more fully" (2005, p. 45). En conclusión:

a) se necesita preparación, estudio y confección de materiales, porque el profesor del curso de cultura y literatura en L2 debe saber mucho más de lo que debe mostrar a sus 
estudiantes, eso necesita tiempo cuantitativo y cualitativo para buscar, seleccionar y leer, y a partir de aquí, planificar su clase y el trabajo en el aula;

b) no hay que tenerle miedo a la literatura en la enseñanza de L2; es un campo lleno de preguntas/estímulos y de satisfacciones tanto para el profesor que se ha preparado por anticipado, como para sus estudiantes, que se entusiasmarán y se sentirán motivados de retorno. De esta manera, el profesor se verá afectado, en su sentido más general y etimológico, no solo por lo que aprenderá de sus estudiantes, sino de lo que él hará en su confrontación con los textos y las demandas cognoscitivas y estéticas de los estudiantes. Se propone una ética de la lectura como una conducta hermenéutica para la enseñanza literaria (Schaeffer, 1986, p. 203).

\section{Notas}

1. Me parece una contradicción que ella pondere aquí el aprendizaje como "proceso acumulativo", porque cuando lo explica lo desarrolla como integrativo: "lo nuevo es aprendido sólo cuando se integra en el conjunto de conocimientos ya existentes en el individuo" (2003, p. 44).

2. Cabe destacar en la enseñanza de la literatura en L2 el papel que desempeña este libro de María Amoretti, surgido de sus clases de cultura y literatura que ella ofreció por muchos años en esta Maestría.

3. Los he resumido yo de esta manera, porque son más los que ella propone.

\section{Bibliografía}

Amoretti-Hurtado, M. (2007). Didáctica de la literatura en la enseñanza de segundas lenguas: Doce modelos didácticos y una discusión. San José: Editorial de la Universidad de Costa Rica.

Barthes, R. (1980). S/Z. México, D.F.: Siglo Veintiuno Editores.

Bertoni Del Guercio, G. (1988). Littératures et système littéraires. Le Français dans le monde. Número especial, 149-156.

Block, P. K. (1985). Introducción a la moderna antropología cultural. México, D. F.: FCE.

Castillo-Víquez, A. E. (2003). Proyecto de práctica. Propuesta metodológica para la enseñanza de la literatura latinoamericana a partir de las claves culturales en una clase de hablantes no nativos del Español. (Tesis de Maestría). Universidad de Costa Rica.

Cros, E. (2003). El sujeto cultural: sociocrítica y psicoanálisis. (2 ed.). Medellín: Fondo Cultural Universidad EAFIT.

Elliot, J. (2005). La investigación-acción en educación. Madrid: Ediciones Morata.

Gueunier, N. (1977). Enseignants du secondaire et nouvelles recherches. Poétique. 30, 135-48.

Hernández-Morales, L. (2004). La enseñanza de la cultura desde una perspectiva pragmáticosituacional. (Tesis de Maestría). Universidad de Costa Rica.

Larsen-Freeman, D. y Long, M. H. (1994). Introducción al estudio de la adquisición de segundas lenguas. Madrid: Editorial Gredos.

Lazar, G. (2005). Literature and Language Teaching: A Guide for Teachers and Trainers. Cambridge: Cambridge University Press. 
Lomas, C. y Miret, I. (1999). La educación poética. Textos de didáctica de la lengua y de la literatura. 21, 5-21.

Montero-Chacón, S. (2004). La enseñanza de la cultura hispanoamericana desde la perspectiva del mestizaje y sus manifestaciones culturales. (Tesis de Maestría). Universidad de Costa Rica.

Pérez-Gómez, Á. (2005). Comprender y enseñar a comprender. Reflexiones en torno al pensamiento de J. Elliot. La investigación-acción en educación. (9-19). Madrid: Ediciones Morata.

Picard, M. (1984). La lecture comme jeu. Poétique. 58, 253-263.

Riffaterre, M. (1979). La production du texte. París: Éditions du Seuil.

Schaeffer, J. M. (1986). La littérature comme fait de valeur. Esprit. 117-118, 202-213.

Swaffar, J. y Arens, K. (2005). Remapping the Foreign Language Curriculum: An Approach through Multiple Literacies. New York: The Modern Language Association of America.

Tiedt, P. L. y Tiedt, I. M. (2002). Multicultural Teaching: A Handbook of Activities, Information and Resources. Boston: Allyn \& Bacon.

Villalobos-Vega, E. M. (2011). El relato corto como artefacto pedagógico. (Tesis de Maestría). Universidad de Costa Rica. 